\title{
Impact of Testing on Sexually Transmitted Infections among Female Brothel Sex Workers in Bangladesh: A Randomized Controlled Trial
}

\author{
Asad Islam, ${ }^{1}$ HongQi Alexis Tan, ${ }^{1}$ Claire C. Bristow, ${ }^{2}$ Md Golam Hasnain, ${ }^{3 *}$ Russell Smyth, ${ }^{1}$ and Liang Choon Wang ${ }^{1}$ \\ ${ }^{1}$ Centre for Development Economics and Sustainability (CDES) and Department of Economics, Monash University, Melbourne, Australia; ${ }^{2}$ Division \\ of Infectious Diseases and Global Public Health, Department of Medicine, University of California San Diego, La Jolla, California; ${ }^{3}$ School of \\ Medicine and Public Health, Faculty of Health and Medicine, University of Newcastle, Newcastle, Australia
}

\begin{abstract}
Past studies that have designed interventions to reduce the prevalence of sexually transmitted infections (STIs) have typically provided onsite treatment to sex workers who tested positive, which were expensive and difficult to implement. The purpose of this study was to examine the effect of an intervention which tested for STIs and provided information on the closest treatment facility on reducing the prevalence of STIs among female brothel-based sex workers (BSWs) in Bangladesh. The study adopted a pre-post interventional design as well as a randomized controlled study design. A baseline sample and follow-up urine sample were collected to evaluate the prevalence of STIs among participants in the treatment, but not control group. A baseline survey and interviews were also conducted for both the groups. The study found a nonsignificant reduction from baseline to follow-up in STI prevalence among intervention participants (adjusted odds ratio [aOR]: $0.74 ; 95 \% \mathrm{Cl}: 0.38,1.45$ ). However, the participants in the intervention group were significantly more likely to have a repeat client (aOR: $1.60 ; 95 \% \mathrm{Cl}: 1.12,2.29)$ and nonsignificantly less likely to engage with a client suspected of having an STI (aOR: $0.62 ; 95 \%$ Cl: $0.39,1.00)$ than participants in the control group. The intervention testing of STIs and providing information to the positive cases about nearest treatment facilities were not effective in reducing the prevalence of STIs among BSWs. Further study of the clinical and behavioral impacts of such efforts to reduce STIs among BSWs is warranted.
\end{abstract}

\section{INTRODUCTION}

Female sex workers (FSWs) are at high risk of acquiring sexually transmitted infections (STIs) and HIV infection. ${ }^{1-4}$ Female sex workers have increased vulnerability to HIV and STIs because of a combination of behavioral and structural factors, including gender power dynamics, gender-based violence, multiple sexual partnerships, stigma, and criminalization, as well as barriers to healthcare access. ${ }^{5-7}$ There are estimated to be 200,000 FSWs in Bangladesh. ${ }^{8}$ These FSWs are distributed across a range of urban and rural communities, working in either a brothel setting or as independent sex workers. ${ }^{9}$ Sexually transmitted infections are considered one of the major public health concerns in many lowincome countries, such as Bangladesh, and sex workers have been identified as one of the most important risk factors for community transmission of STIs in Bangladesh. ${ }^{10}$ Some crosssectional studies and serological surveys have reported a high prevalence of STIs, ranging from $8 \%$ to $64 \%$, among FSWs in Bangladesh. ${ }^{11}$ Therefore, it is important to design an appropriate intervention that will reduce the prevalence of STIs among FSWs and curtail their risk-taking behaviors.

Interventions have been designed to reduce the burden of STIs/HIV among FSWs in several developing countries. ${ }^{12}$ Those interventions have included increasing the use of condoms among clients ${ }^{13-18}$ and encouraging FSWs to practice protected sex alongside regular STI/HIV testing. ${ }^{19-26}$ Some of these studies have measured the prevalence of STIs/ HIV among FSWs at baseline and follow-up, to examine the effectiveness of the interventions. These studies have typically provided onsite treatment to FSWs in the event that they tested positive for STIS/HIV at baseline. For example, FSWs in India who tested positive for Chlamydia trachomatis (CT) or

* Address correspondence to Md Golam Hasnain, School of Medicine and Public Health, University of Newcastle, Level 3 East, HMRI Building, Lot 1, Kookaburra Circuit, New Lambton Heights NSW 2305, Australia. E-mail: mdgolam.hasnain@uon.edu.au
Neisseria gonorrhoeae (NG) were treated with azithromycin and cefixime, respectively, in a study conducted by Ramesh and others. ${ }^{27}$ However, those interventions may not be feasible because of the high cost associated in dispatching mobile teams of medical personnel to reach what is a dispersed target group, especially for resource-limited countries ${ }^{28}$ In addition, studies that have provided onsite STIS/HIV treatment at baseline may have overestimated the impact of the intervention. As a lack of access to health care among FSWs is a common problem, especially in developing countries such as Bangladesh, reflecting financial constraints and embarrassment felt when visiting healthcare providers, FSWs may not actually seek treatment for STIs/HIV. ${ }^{5}$ Viable alternatives for FSWs to obtain treatment should be identified and systematically evaluated so that limited resources can be allocated for maximum impact. However, no such interventions have so far been tested in Bangladesh. Therefore, this study evaluated the effect of a simple intervention which included testing for the presence of STIs in urine samples, providing FSWs with the result of the urine test and, finally, informing STI-infected FSWs of the closest medical facility at which they could seek treatment.

The primary aim of our study was to examine the change in STI prevalence among female brothel-based sex workers (BSWs) in Bangladesh, located at Mymensingh and Tangail, before and after an STI testing intervention to test BSWs for STIs while providing those STI-infected BSWs with information on the closest clinics at which they could seek STI treatment. Given the risk factors that $\mathrm{FSWs}$ pose for community transmission, we also examined the impact of STI testing on the sex work behaviors of BSWs in our study. These results can be used to inform future research to formulate appropriate initiatives to complement the effects that arise from STI/HIV testing among FSWs.

\section{MATERIALS AND METHODS}

Design. We conducted a randomized controlled trial of CT and NG testing (also referred to as a STI test) at two brothels 
located in two cities-Mymensingh and Tangail-in Bangladesh. Between February 21, 2016 and March 5, 2016, 467 BSWs from the brothels located in these cities were recruited at baseline (Figure 1). We used the CT PCR kit and NG PCR kit (GeneProof, Brno, Czech Republic) to detect the presence of CT and NG, respectively, in urine samples of the BSWs. The randomized controlled trial $(\mathrm{RCT})$ is registered: ACTRN12617001250325. Ethical and institutional approval were obtained from the respective institutions (CF 13/3517-2013001769).

Participants. Baseline surveys at the brothels in Mymensingh and Tangail were administered to participants between February and March 2016 (Supplemental Table 1). The survey included questions on demographic profile, occupational information, and the health awareness of participants with respect to STIs. Participants were interviewed on details about their last 3 days' commercial sex transactions and their last three commercial sex transactions, which included questions about condom use and characteristics of their clients. To minimize recall bias, surveyors provided sufficient time to all respondents to allow them to correctly recall past clients and their characteristics. All of our interviewers were well trained in working with such a challenging community and vulnerable population as well as collecting long recall data from respondents. The survey also covered questions on whether the participant had been trafficked into the sex work industry and the risk tolerance of the participant in general and with respect to their health, for which they were asked to answer on a scale of 0-10 ("0" means risk averse and "10" means risk prone). The health anxiety of participants was derived from participants' responses on questions obtained from the 18-item Health Anxiety Inventory. ${ }^{29}$

Enumerators commenced the sampling process at the entrance of each brothel before spreading across the entire brothel. As brothels in Bangladesh consist of groups of small rented rooms, we grouped rooms in a brothel that were close to one another together (Supplemental Figures 1 and 2) and labeled them a "building" for the purpose of data analysis. This yielded a total of 54 buildings, consisting of seven buildings in the Mymensingh brothel and 47 buildings in the Tangail brothel.

Enumerators were instructed to sample BSWs who met the following criteria: 1) aged between 17 and 36 years, 2) must

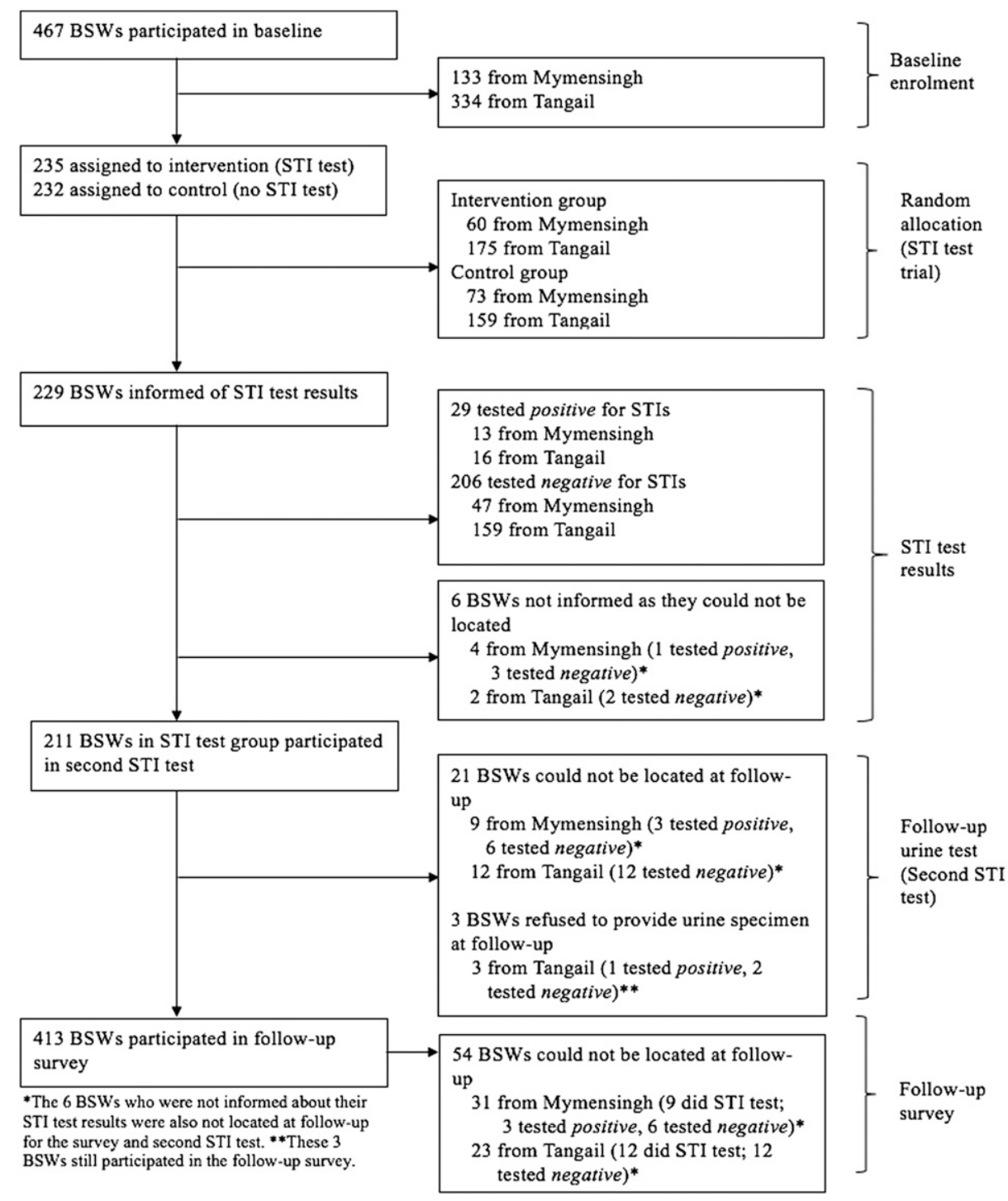

FigurE 1. Study profile of female brothel sex workers, Mymensingh and Tangail, Bangladesh. 
have engaged in a commercial sexual transaction in the past 3 days, and 3) not be pregnant. The age restriction was introduced to ensure that the average age of our baseline sample aligns with the average age of BSWs (approximately 24 years old) reported in the literature. ${ }^{30}$ The no-pregnancy criterion was used to avoid the possibility that pregnant BSWs may refrain from engaging in sexual transactions, thus affecting the collection of information on transactions at follow-up. This recruitment procedure returned a baseline sample of 467 BSWs. All participants in our study provided verbal consent.

Randomization and masking. The 467 participants at baseline were randomly assigned to the intervention group (STI testing; $n=235$ ) or the control group (no STI testing; $n=$ 232) of the STI test trial (Figure 1) after the baseline survey was completed. Randomization was conducted at the individual sex worker level. A list of random numbers was generated with Stata software (version 14, College Station, TX) to assign the participants to trial groups.

Participants were masked to each other's trial assignment. Intervention participants were informed of their assignment individually in private in their respective rooms at the time of the trial. Enumerators, International Centre for Diarrhoeal Disease Research, Bangladesh (icddr,b), and data analysts were not masked to the assignment of participants.

Experimental procedure. Before the baseline survey was conducted, all enumerators employed in our study were given training on techniques to interview BSWs.

The night before the STI test trial was scheduled, two urine collectors handed out urine bottles to participants in the intervention group in private in each of their respective rooms and instructed them to use the bottles to collect their first morning urine. The urine collectors visited the brothels the following morning to collect the urine specimens. The urine specimens were promptly deposited into coolers and transported to the icddr,b by the urine collectors. The urine specimens were stored at $4^{\circ} \mathrm{C}$ at icddr,b until they were tested for the presence of CT and NG. The urine collectors were trained by icddr,b on the collection and safe-keeping of the urine specimens. The urine for the baseline test was collected between May and June 2016 (Supplemental Table 1).

Urine test results were released to us by icddr,b on August 19, 2016 (Mymensingh sample) and August 29, 2016 (Tangail sample) (Supplemental Table 1). There was a significant time period between the collection of urine samples and the release of the STI results due to a shortage of the CT and NG PCR kits at icddr,b. A participant who had her urine tested was classified as positive if the test results were positive for either CT or $N G$ and negative if all results were negative. A certified clinician visited Mymensingh and Tangail on August 24, 2016 and September 2, 2016, respectively, to inform participants of their test results in private in each of their rooms. The urine collectors assisted the clinician in locating the participants. The clinician was also responsible for advising STI-positive participants on where to seek treatment by providing them both written and verbally with the names and addresses of the closest clinics, with at least one of the clinics located within $1 \mathrm{~km}$ from the brothel in which the BSW was working. The research team did not follow-up with the BSWs regarding their visits to clinics. All tested participants were informed about their test results, but only the positive cases were provided with information about the location of the nearest clinic and advised to seek treatment at that clinic.
Both the follow-up survey and the second STI test were conducted with participants in November 2016, approximately 2-3 months after results were delivered to participants. The second urine collection followed the same procedure carried out in the first urine collection and was conducted only among those in the intervention group. The follow-up survey was conducted by the enumerators with all participants after the urine specimens had been collected by the urine collectors. We refer to the STI results from the first and second urine tests as the baseline and follow-up STI results, respectively.

Statistical justification for sample size. Prior studies found a $51 \%$ reduction in STI prevalence among FSWs in Bangladesh when onsite STI treatment was provided. ${ }^{31}$ As our study provided participants in the intervention group who tested STI-positive with information on where to seek STI treatment in lieu of onsite STI treatment, we considered a more conservative $25 \%$ reduction in STI prevalence among participants at follow-up to be an appropriate target.

We used the Optimal Design software ${ }^{32}$ (William T Grant Foundation, New York, NY) to calculate the minimum number of participants needed to detect a $25 \%$ reduction in STI prevalence between intervention and control participants with $90 \%$ confidence and $80 \%$ power. We estimated that the minimum number of participants required was 365 . With our sample size of more than 400 sex workers after accounting for attrition, we have sufficient power to detect the group assignment effects.

Statistical analysis. The primary outcome of our STI test trial focused on the change in STI prevalence of participants in the intervention group only. The key secondary outcomes focused on the sex work behavior of participants in the intervention and control groups as reported in their last 3 days' commercial sexual transactions and last three transactions at follow-up. A description of the sex work behaviors of sex workers can be found in the Supplementary Material (Supplemental Table 2).

Primary outcome (STI prevalence). We estimated the following logistic regression model:

$$
F\left(\text { STI_Positive }_{i}\right)=\frac{1}{1+e^{- \text {STI_Positive }_{i}}},
$$

where STI_Positive $i=\beta_{0}+\beta_{1}$ Follow $_{-} \mathrm{Up}_{i}+\beta_{2} X_{i}+\varepsilon_{i}$,

where $F($.$) refers to the cumulative standard logistic distribu-$ tion function. The outcome variable, STI_Positive ${ }_{i}$, is a dummy variable that takes the value one if participant $i$ tested positive for STIs (CT and/or NG), and 0 if she tested negative for STIs. The explanatory variable, Follow_Up ${ }_{i}$, is a dummy variable that takes the value one if the STI result of participant $i$ is measured at follow-up, and 0 if the STI result is measured at baseline. $X_{i}$ is a set of control variables of the characteristics of participant $i$. $\varepsilon_{i}$ is the error term.

Secondary outcomes (sex work behavior). We measured the impact of the STI test trial by estimating the following ordinary least squares (OLS)/logistic regression model:

$$
Y_{i}=\alpha_{0}+\alpha_{1} \text { Intervention }_{i}+\alpha_{2} X_{i}+\varepsilon_{i},
$$

or

$$
F\left(Y_{i}\right)=\frac{1}{1+e^{-Y_{i}}},
$$

where $Y_{i}=\alpha_{0}+\alpha_{1}$ Intervention $_{i}+\alpha_{2} X_{i}+\varepsilon_{i}$, 
where $Y_{i}$ refers to the key secondary outcome. Intervention ${ }_{i}$ is a dummy variable that takes the value one if participant $i$ is assigned to the intervention group, and 0 if the participant is assigned to the control group. $X_{i}$ is a set of control variables of the characteristics of participant $i . \varepsilon_{i}$ is the error term. Information related to the last three transactions, for example, number of clients, proportion of repeat clients, and clients using condoms; information related to client characteristics, for example, wealthy client, educated client, and attractive client; and overall risk attitude, heath risk attitude, and anxiety scores were considered as secondary outcome variables. The logistic regression model is only used for secondary outcomes with dichotomous values.

Spillover effects. Participants located in rooms that are close to one another (e.g., in the same building) may share similar (unobserved) characteristics that may differ from those of participants in rooms that are far apart. To account for this possibility, we clustered the standard errors of the estimates at the building level. There was natural variation in the percentage/intensity of participants assigned to the intervention across the buildings (Supplemental Figure 3), between 0\% and $100 \%$, during randomization. We measured the spillover effects of our STI test trial on the sex work behavior of participants by first creating the following variable for each building:

$$
\begin{aligned}
& \text { Intensity_Intervention } \\
& =\frac{\text { Number of participants assigned to intervention }}{\text { Total number of participants }} .
\end{aligned}
$$

We then measured the spillover effects on subsamples (i.e., control participants only and intervention participants only) in our study by estimating the following OLS regression model:

$$
Y_{i}=\varnothing_{0}+\phi_{1} \text { Intensity_Intervention } i+\varnothing_{2} X_{i}+\varepsilon_{i}
$$

or

$$
F\left(Y_{i}\right)=\frac{1}{1+e^{-Y_{i}}}
$$

where $Y_{i}=\varnothing_{0}+\varnothing_{1}$ Intensity_Intervention $i+\varnothing_{2} X_{i}+\varepsilon_{i}$,

where $Y_{i}$ refers to the key secondary outcome. $X_{i}$ is a set of control variables of the characteristics of participant $i . \varepsilon_{i}$ is the error term. The logistic regression model is only used for secondary outcomes with dichotomous values.

\section{RESULTS}

Sample and trial progression. Analyses of the primary outcome were conducted for the 211 participants in the intervention group that completed follow-up, whereas analyses of the secondary outcomes were conducted for the 413 participants in the control and intervention groups that completed follow-up.

Table 1 shows the baseline characteristics of the intervention and control groups. The mean age of participants was 25.0 years $(S D=5.1)$, and participants had 2.5 years of education (SD $=3.1)$. More than half $(n=263,56 \%)$ of the participants were trafficked into the sex work industry and had an average of 7 years of sex work experience (SD = 5.5). Participants believed that, on average, around 30\% (SD = 25.5) of their clients were STI-positive and that, on average, the likelihood that they themselves were STI-positive was two (SD = 2.6) on a scale of 0-10 ("0" means sure that she does not have an STI and "10" means sure that she does have an STI). Participants earned an average of 330 Taka (US\$4.14) per client (SD = 124.8 Taka [US\$1.56]) (based on the exchange rate on March 5, 2016, using OANDA Currency Converter, Oanda Corporation, New York, NY). Less than half of the participants' clients were repeat clients, and $90 \%$ of clients used condoms. Baseline characteristics of the intervention and control groups of the trial were generally similar and balanced at randomization. The baseline characteristics between the two groups were also balanced at randomization by brothel (Supplemental Table 3) and when we excluded clustering at the building level (Supplemental Table 4).

A total of 24 participants (10\%) in the intervention group did not undergo STI testing at follow-up (Figure 1). A total of 54 participants $(12 \%)$ from both the intervention and control groups did not participate in the follow-up survey as they could not be located. A higher number of participants from the control group ( $n=33$ ) were lost to the follow-up than those in the intervention group $(n=24)$. The baseline characteristics of participants who dropped out between the intervention and control groups were generally similar (Supplemental Table 5).

Outcome results. Table 2 shows the prevalence of STIs among participants in the intervention group, both at baseline and at follow-up. The result shows a nonsignificant $26 \%$ reduction in STI prevalence among intervention participants (adjusted odds ratio [aOR]: $0.74 ; 95 \% \mathrm{Cl}$ : 0.38, 1.45) compared with the control participants.

Table 3 shows the impact of the trial on the sex work behavior (reported at follow-up) of participants. Participants in the intervention group had a statistically significant higher odds of having a repeat client (aOR: $1.60 ; 95 \% \mathrm{Cl}: 1.12,2.29$ ) and a nonsignificant lower odds of engaging with a client suspected of having an STI (aOR: 0.62; 95\% CI: 0.39, 1.00) than participants in the control group. Participants in the intervention group were also more risk tolerant, both in general (adjusted difference: 0.46 ; 95\% Cl: $0.05,0.86$ ) and specifically with respect to their health (adjusted difference: $0.39 ; 95 \% \mathrm{Cl}$ : $0.08,0.70$ ).

Table 4 shows the spillover effects of the STI test trial. The behavioral coefficients are large. For instance, participants in the control group had fewer repeat clients as the intensity of participants assigned to intervention increases (adjusted difference: $-22.1 \%$; 95\% Cl: $-54.00,+9.77)$. Our results also suggest that, on average, as the intensity of participants assigned to intervention increases, intervention participants had fewer clients (adjusted difference: $-2.88 ; 95 \%$ Cl: $-6.07,+0.32)$.

\section{DISCUSSION}

We have reported the effect of a simple intervention (testing STIs among BSWs and providing information about the nearest treatment facilities to the positive cases) in reducing the prevalence of STIs and risky sex behaviors among BSWs. This is the first study to combine both testing for STIs and providing information about treatment facilities as a potential cost-effective approach to improve the health outcomes, and risky sex behaviors, of BSWs in a developing country context. The intervention did not show any statistically significant effect in reducing the prevalence of STIs among BSWs. 
TABLE 1

Baseline characteristic of female brothel sex workers, Mymensingh and Tangail, Bangladesh

\begin{tabular}{|c|c|c|c|}
\hline \multirow[b]{2}{*}{ Baseline characteristics of BSWs $(\mathrm{N}=467)$} & \multicolumn{2}{|c|}{ Mymensingh \& tangail } & \multirow[b]{2}{*}{$P$-value (intervention vs. control) } \\
\hline & Control $(n=232)$ & Intervention $(n=235)$ & \\
\hline Beauty (on a scale of 1-4) & $3.3(0.7)$ & $3.2(0.7)$ & 0.15 \\
\hline Age (years) & $24.6(5.1)$ & $25.1(5.1)$ & 0.23 \\
\hline Education (years) & $2.7(3.3)$ & $2.3(3.0)$ & 0.19 \\
\hline Ever married, $n(\%)$ & $144(62)$ & $142(60)$ & 0.69 \\
\hline Ever had children, $n(\%)$ & $107(46)$ & $93(40)$ & 0.14 \\
\hline Father alive, $n(\%)$ & $126(54)$ & $124(53)$ & 0.58 \\
\hline Mother alive, $n(\%)$ & $156(67)$ & $168(71)$ & 0.40 \\
\hline Mother is/was a sex worker, $n(\%)$ & $25(11)$ & $34(14)$ & 0.17 \\
\hline Trafficked into sex work industry, $n(\%)$ & $127(55)$ & $136(58)$ & 0.49 \\
\hline Managed by a sardarnis/brothel madam, $n$ (\%) & $20(8.6)$ & $17(7.2)$ & 0.47 \\
\hline Time in sex work (years) & $7.1(5.7)$ & $7.6(5.3)$ & 0.32 \\
\hline Regular test for STIs, $n$ (\%) & $173(75)$ & $165(70)$ & 0.36 \\
\hline STI likelihood (on a scale of $0-10$ ) & $1.7(2.5)$ & $1.7(2.8)$ & 0.81 \\
\hline STI anxious (on a scale of $0-10$ ) & $7.0(3.3)$ & $7.3(3.1)$ & 0.19 \\
\hline STI belief (on a scale of $0-100$ ) & $30.2(25.9)$ & $28.2(25.1)$ & 0.36 \\
\hline Ever watched video on STIs or HIV/AIDS, $n(\%)$ & $101(44)$ & $110(47)$ & 0.48 \\
\hline Ever smoked, $n(\%)$ & $125(54)$ & $114(49)$ & 0.19 \\
\hline Ever consumed alcohol, $n$ (\%) & $100(43)$ & $102(43)$ & 0.94 \\
\hline Ever used drugs & $90(39)$ & $72(31 \%)$ & 0.087 \\
\hline Health test score & $8.4(3.8)$ & $8.5(4.0)$ & 0.72 \\
\hline Satisfied with life (on a scale of $0-10$ ) & $5.3(3.3)$ & $5.3(3.2)$ & 0.95 \\
\hline Esteem (on a scale of $1-5$ ) & $3.4(1.0)$ & $3.4(1.0)$ & 0.99 \\
\hline Extraversion & $0.3(1.9)$ & $0.3(1.8)$ & 0.72 \\
\hline Agreeableness & $1.6(1.2)$ & $1.6(1.2)$ & 0.90 \\
\hline Conscientiousness & $1.2(1.4)$ & $1.1(1.3)$ & 0.42 \\
\hline Neuroticism & $-0.1(1.7)$ & $-0.1(1.5)$ & 0.82 \\
\hline Openness & $0.1(1.5)$ & $0.1(1.5)$ & 0.79 \\
\hline Friendly (on a scale of $1-5$ ) & $4.1(0.8)$ & $4.1(0.8)$ & 0.98 \\
\hline Communicates well (on a scale of $1-5$ ) & $4.0(0.8)$ & $4.0(0.9)$ & 0.59 \\
\hline Overall risk attitude (on a scale of $0-10$ ) & $4.5(3.1)$ & $4.4(3.2)$ & 0.81 \\
\hline Health risk attitude (on a scale of $0-10$ ) & $3.4(3.1)$ & $3.2(3.2)$ & 0.56 \\
\hline \multicolumn{4}{|l|}{ Last 3 days' transactional information } \\
\hline Total income $(\text { Taka })^{\star}$ & $3044.4(2,485.2)$ & $3075.2(2,475.9)$ & 0.88 \\
\hline Total clients & $9.8(8.0)$ & $9.5(7.0)$ & 0.64 \\
\hline Total condoms used & $9.0(7.8)$ & $8.6(6.3)$ & 0.63 \\
\hline Price per client $(T a k a)^{\star}$ & $324.7(124.2)$ & $331.4(125.6)$ & 0.57 \\
\hline Percentage of regular clients & $34.2(34.4)$ & $33.8(35.7)$ & 0.90 \\
\hline Percentage of clients suspected of having STIs & $7.9(22.9)$ & $7.3(20.9)$ & 0.73 \\
\hline Percentage of clients using condom & $91.3(20.1)$ & $93.1(18.2)$ & 0.31 \\
\hline
\end{tabular}

However, the intervention showed statistically significant effects in changing the risk-taking behaviors of BSWs, such as engaging repeat clients and avoiding clients suspected of having STIs.

Several studies have provided onsite STI treatment to FSWs who test positive for STls at baseline. In this study, we assessed the effectiveness of an alternative approach, which entailed providing information on the closest clinic at which BSWs, who tested positive for STls at baseline, could seek treatment. Although we find that providing such treatment information to STI-positive BSWs resulted in a nonsignificant reduction in STI prevalence among BSWs in the intervention group at follow-up, our finding of a reduction in STI prevalence is consistent with interventions that have provided onsite treatment to STI-positive FSWs. ${ }^{14,15}$ The magnitude of the reduction in STI prevalence in our study, however, is not statistically significant and generally smaller than that reported in studies that provided onsite treatment. One study ${ }^{31}$ reported a $51 \%$ drop in STI prevalence among FSWs in Bangladesh. The smaller reduction in our study likely reflects the fact that some BSWs might be reluctant to seek treatment. Several causes might be responsible for this reluctance of BSWs to seek medical treatment as described in the previously published literature, ${ }^{5,33}$ including fear of being discriminated, not wanting to take time off work for fear of losing clients, and the lack of money to pay for treatment. The finding reported in this study might also be due to STI reinfection in BSWs who had already sought STI treatment. Future interventions should also target clients and other sex partners of BSWs for identification and treatment of STIs.

One of the limitations of the design is that we did not measure the STI prevalence of participants in the control group at follow-up due to shortage of funds. We were, therefore, unable to estimate the full impact of providing BSWs with information on where to seek treatment on STI prevalence. We were also not able to add an intervention to provide onsite treatment for STIs to gage the difference between the effectiveness of onsite treatment and giving BSWs information on the nearest 


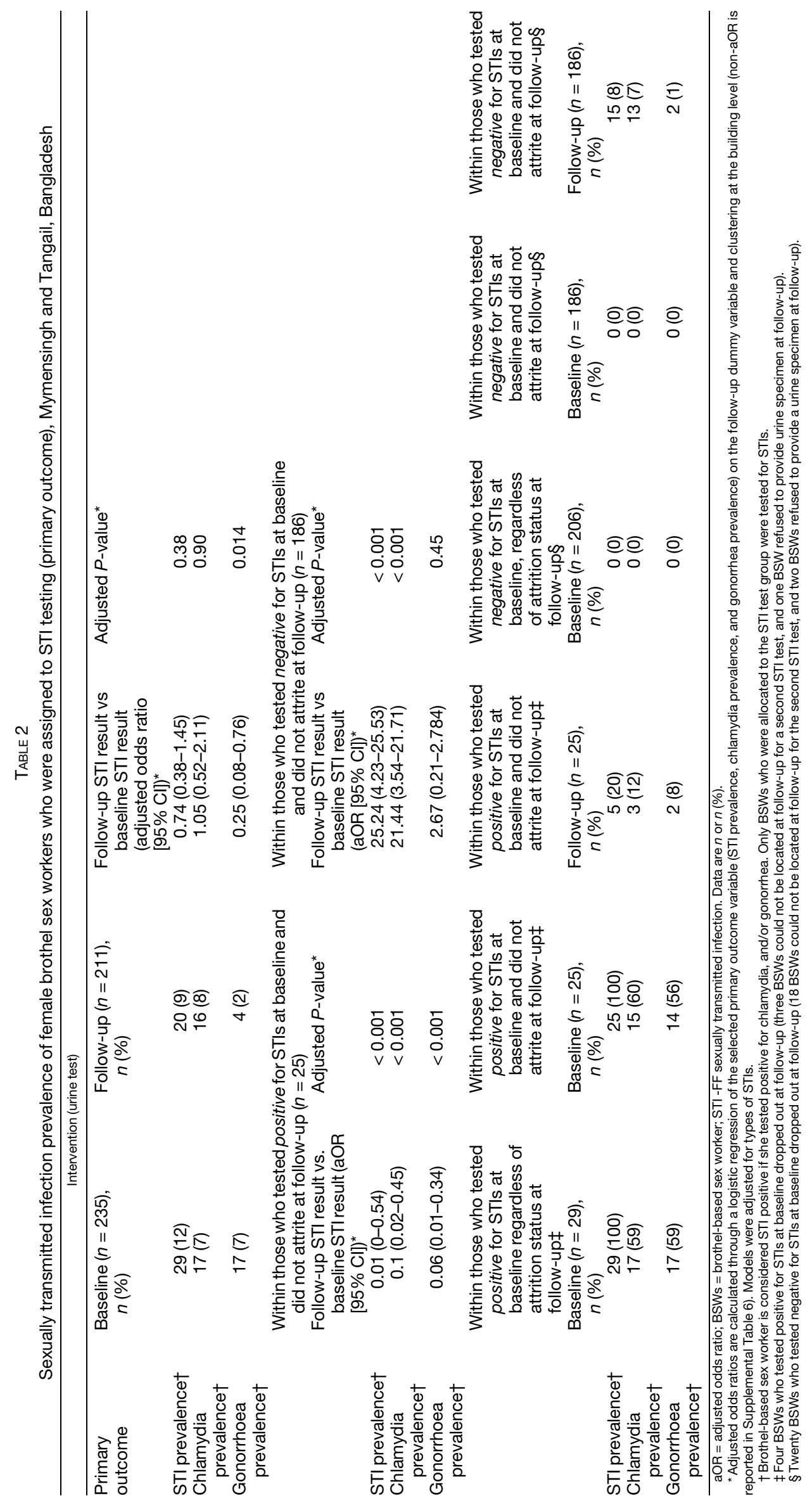


TABLE 3

Sex work behavior of female brothel sex workers, Mymensingh and Tangail, Bangladesh

\begin{tabular}{|c|c|c|}
\hline Secondary outcome & 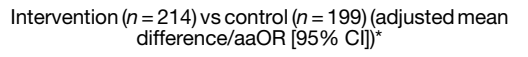 & Adjusted $P$-value ${ }^{*}$ \\
\hline \multicolumn{3}{|c|}{ Last 3 days' transactional information (results are in mean difference) $†$} \\
\hline Total number of clients & $-0.10(-1.24-1.03)$ & 0.86 \\
\hline Proportion of repeat clients (\%) & $6.30(-1.07-13.66)$ & 0.09 \\
\hline Proportion of clients suspected of having STIs (\%) & $-0.60(-3.58-2.38)$ & 0.69 \\
\hline Proportion of clients using condom (\%) & $-1.14(-5.35-3.06)$ & 0.59 \\
\hline \multicolumn{3}{|l|}{ Last three transactions (results are in OR)†,‡ } \\
\hline Used a condom & $0.90(0.41-1.98)$ & 0.79 \\
\hline Used a condom with all three clients & $0.91(0.46-1.79)$ & 0.79 \\
\hline Used a condom with at least two clients & $0.68(0.17-2.77)$ & 0.59 \\
\hline Used a condom with at least one client & $1.77(0.20-15.6)$ & 0.61 \\
\hline Had a repeat client & $1.60(1.12-2.29)$ & 0.01 \\
\hline Had a client suspected of having STIs & $0.62(0.39-1.00)$ & 0.05 \\
\hline Inspected client for STIs & $0.81(0.50-1.30)$ & 0.38 \\
\hline Had a wealthy client & $1.08(0.83-1.39)$ & 0.57 \\
\hline Had an educated client & $0.93(0.68-1.26)$ & 0.63 \\
\hline Had an attractive client & $1.02(0.78-1.32)$ & 0.91 \\
\hline Had a clean client & $0.81(0.43-1.55)$ & 0.53 \\
\hline Liked the client & $1.07(0.82-1.39)$ & 0.63 \\
\hline \multicolumn{3}{|l|}{ Others (results are in mean difference) } \\
\hline Overall risk attitude (on a scale of $0-10$ ) & $0.46(0.05-0.86)$ & 0.03 \\
\hline Health risk attitude (on a scale of $0-10$ ) & $0.39(0.08-0.70)$ & 0.02 \\
\hline Anxiety score§ & $1.76(0.84-2.68)$ & 0.00 \\
\hline
\end{tabular}

clinics to seek treatment. The reduction in the prevalence of STIs among those in the intervention group in our study, however, suggests that providing BSWs with information on where to seek STI treatment may be a promising alternative, but it requires more extensive and larger scale evaluation to confirm its effectiveness. Moreover, we chose to conduct the STI test with BSWs only as they are easier to locate, to conduct a follow-up interview, than street sex workers who are more prone to site relocation. Therefore, our results may not be generalizable to other FSWs that are not brothel based. Future

TABLE 4

Spillover effects of STI testing on the sex work behaviors of female brothel sex workers, Mymensingh and Tangail, Bangladesh

\begin{tabular}{|c|c|c|c|c|}
\hline Secondary outcome & $\begin{array}{l}\text { Intensity of BSWs assigned to intervention } \\
\text { on control group (n= 1999) (adjusted mean } \\
\text { difference/adjusted odds ratio }[95 \% \text { CII] })^{*}\end{array}$ & $\begin{array}{l}\text { Adjusted } \\
P \text {-value }\end{array}$ & $\begin{array}{l}\text { Intensity of BSWs assigned to intervention } \\
\text { on intervention group }(n=214) \text { (adjusted } \\
\text { mean difference/adjusted odds ratio [95\% CII]) }\end{array}$ & $\begin{array}{l}\text { Adjusted } \\
P \text {-value }\end{array}$ \\
\hline \multicolumn{5}{|l|}{$\begin{array}{l}\text { Last } 3 \text { days' transactional information (results are in } \\
\text { mean difference) } \dagger\end{array}$} \\
\hline Total number of clients & $-1.77(-5.87-2.33)$ & 0.39 & $-2.88(-6.07-0.32)$ & 0.08 \\
\hline Proportion of repeat clients (\%) & $-22.11(-54.00-9.77)$ & 0.17 & $6.00(-38.27-50.28)$ & 0.79 \\
\hline Proportion of clients suspected of having STIs (\%) & $6.82(-10.20-23.85)$ & 0.42 & $-7.44(-26.85-11.98)$ & 0.45 \\
\hline Proportion of clients using condom (\%) & $4.71(-8.85-18.28)$ & 0.49 & $-7.41(-28.20-13.38)$ & 0.48 \\
\hline \multicolumn{5}{|l|}{ Last three transactions (results are in OR) + , } \\
\hline Used a condom & $5.21(0.38-72.3)$ & 0.22 & $0.36(0.04-3.50)$ & 0.38 \\
\hline Had a repeat client & $0.47(0.07-3.05)$ & 0.43 & $2.07(0.31-13.78)$ & 0.45 \\
\hline Had a client suspected of having STIs & $1.26(0.09-17.4)$ & 0.86 & $0.50(0.02-11.85)$ & 0.67 \\
\hline Inspected client for STIs & $0.28(0.06-1.37)$ & 0.12 & $0.99(0.13-7.76)$ & 1.00 \\
\hline Had a wealthy client & $0.90(0.28-2.94)$ & 0.86 & $2.20(0.75-6.49)$ & 0.15 \\
\hline Had an educated client & $1.56(0.32-7.50)$ & 0.58 & $0.70(0.28-1.73)$ & 0.44 \\
\hline Had an attractive client & $0.81(0.22-2.98)$ & 0.75 & $1.52(0.51-4.51)$ & 0.45 \\
\hline Had a clean client & $0.25(0.01-9.10)$ & 0.45 & $2.26(0.25-20.38)$ & 0.47 \\
\hline Liked the client & $0.58(0.22-1.54)$ & 0.28 & $1.33(0.50-3.57)$ & 0.57 \\
\hline \multicolumn{5}{|l|}{ Others (results are in mean difference) } \\
\hline Overall risk attitude (on a scale of $0-10$ ) & $-0.94(-3.57-1.69)$ & 0.48 & $0.27(-1.88-2.42)$ & 0.80 \\
\hline Health risk attitude (on a scale of $0-10$ ) & $0.51(-1.66-2.68)$ & 0.64 & $0.56(-0.97-2.09)$ & 0.46 \\
\hline Anxiety score§ & $-0.25(-5.35-4.86)$ & 0.92 & $-2.15(-6.70-2.40)$ & 0.35 \\
\hline \multicolumn{5}{|c|}{$\begin{array}{l}\text { BSW = brothel-based sex worker. } \\
\text { "Adjusted mean difference (calculated for Last } 3 \text { days' transaction information and Others)/adjusted odds ratio (calculated for Last three transactions) calculated via a linear/logistic regression of } \\
\text { selected secondary outcome variable on the proportion of BSWs assigned to the intervention group, pre-intervention-level outcomes, and clustered at the building level (non-adjusted mean } \\
\text { difference is reported in Supplemental Table 8). } \\
\text { † Seven BSWs reported no transactions in the last } 3 \text { days. } \\
\text { †Listed secondary outcomes are binary outcomes. } \\
\text { \& Anxiety score is derived from the Health Anxiety Inventory, the higher the score the higher the anxiety. No adjustment for baseline measure because data were not collected at baseline. Overall } \\
\text { risk attitude ("0" means risk averse and "10" means risk prone). Health risk attitude ("0" means risk averse and "10" means risk prone). }\end{array}$} \\
\hline
\end{tabular}


studies could include an STI test for the control group at follow-up to more accurately measure the impact of providing such treatment information to BSWs, and also extending the trial to non-brothel-based FSWs.

Our results also showed that testing for STIs may have had the positive effect of encouraging BSWs to engage repeat clients and avoid clients suspected of having STIs. Engaging more with repeat clients reduces BSWs' exposure to new clients, which could lower the risk of BSWs being infected with STIs. ${ }^{34}$ However, our analyses showed that BSWs in the intervention group became more risk tolerant toward their health. This result is inconsistent with them exhibiting safer sexual behaviors. The increase in self-perceived risk tolerance may be due to the possibility that STI testing made the risks associated with sex work more salient to BSWs. ${ }^{35}$ As such, BSWs may have realized that their behavior was riskier than how they originally perceived it to be and, thus, subsequently revised their perception of their risk tolerance upward.

Finally, for the primary outcome of interest (the prevalence of STIs), only the pre-post intervention evaluation was conducted, given that we did not have a control group available for comparison. The results about the clients' characteristics could be subject to recall bias despite our best efforts to minimize such. Therefore, the results of this intervention should be interpreted with caution. Although there was a randomly assigned control group for drawing causal inferences about the effects of the intervention on risky sex behaviors, the relatively short duration of the intervention (2-3 months) means that the intervention may not be sufficiently strong for behavioral changes to take place. This may explain why the effect on reducing STIs is not particularly strong, even when there is suggestive evidence that BSWs take less risk with respect to the clients with whom they engage. A final limitation is the potential for contamination between the intervention and control groups because participants in both the intervention and control groups reside in the same location. Therefore, a further large-scale well-designed study such as a clustered RCT with repeated interventions that runs for a longer period of time may help to identify a more effective, generalizable, and sustainable solution.

\section{CONCLUSION}

The results reported here highlight that once-off testing of BSWs for STIs and providing positive cases with information about nearby medical facilities at which they can seek treatment is unlikely to result in significant changes in the prevalence of STIs. Despite the intervention having a nonsignificant effect on the primary outcome of the study, it suggests that BSWs respond to the intervention by taking less risk with respect to the clients with whom they engage. The key contribution of this study is shedding light on the broad limitations of such a simple intervention in reducing the prevalence of STIs in a developing country context. More importantly, the research points out potential areas in which future interventions can focus to effect behavioral changes. A systematic, and in-depth, qualitative and quantitative evaluation of already implemented interventions is warranted to help develop a more effective and generalizable intervention to reduce STIs in marginalized populations in the future.
Received August 2, 2020. Accepted for publication February 2, 2021.

Published online April 5, 2021.

Note: Supplemental information, tables, and figures appear at www. ajtmh.org.

Acknowledgments: We thank our local NGO collaborators (GDRI and PIACT Bangladesh), International Centre for Diarrhoeal Disease Research, Bangladesh (icddr,b), for assisting with the administration of the experiments, urine tests, and surveys. We thank Monash University, GDRI in Bangladesh, and National Institutes of Health in the United States for generous financial support. We thank Klaus Abbink, Gaurav Datt, Lata Gangadharan, Phil Grossman, Dennis Petrie, Agne Suziedelyte, conference participants at the Australasian Development Economics Workshop at Deakin University, and seminar participants at Monash University for their helpful suggestions. Firoz Ahmed, Mujahid Islam, Foez Mojumder, and Tanvir Rizve provided excellent research support. We also thank the executive director of PIACT (Abu Yusuf Choudhury) and chairman of GDRI (Rafiq Islam) for their support.

Financial support: This study received financial support from Monash University, GDRI in Bangladesh, and National Institutes of Health.

Authors' addresses: Asad Islam, HongQi Alexis Tan, Russell Smyth, and Liang Choon Wang, Department of Economics, Monash University, Melbourne, Australia, E-mails: asadul.islam@monash.edu, tan hongqi@hotmail.com, russel.smith@monash.edu, and liang.c.wang@ monash.edu. Claire C. Bristow, Division of Infectious Diseases and Global Public Health, Department of Medicine, University of California San Diego, La Jolla, CA, E-mail: cbristow@ucsd.edu. Md Golam Hasnain, School of Medicine and Public Health, University of Newcastle, Newcastle, Australia, E-mail: mdgolam.hasnain@uon.edu.au.

\section{REFERENCES}

1. Shannon Ket al., 2014. Global epidemiology of HIV among female sex workers: influence of structural determinants. Lancet 385 : $55-71$.

2. UNAIDS, 2017. HIV Prevention Among Key Populations. Available at: http://www.unaids.org/en/resources/presscentre/featurestories/ 2016/november/20161121_keypops. Accessed July 20, 2017.

3. World Health Organization, United Nations Population Fund, Joint United Nations Programme on HIV/AIDS, Global Network of Sex Work Projects, The World Bank, 2013. Implementing Comprehensive HIVISTI Programmes with Sex Workers: Practical Approaches from Collaborative Interventions. Geneva, Switzerland: WHO. Available at: http://apps.who.int/iris/ bitstream/10665/90000/1/9789241506182_eng.pdf. Accessed July 20, 2017.

4. Steen R, Wi TE, Kamali A, Ndowa F, 2009. Control of sexually transmitted infections and prevention of HIV transmission: mending a fractured paradigm. Bull World Health Organ 87: 858-865.

5. Wahed T, Alam A, Sultana S, Rahman M, Alam N, Martens M, Somrongthong $R, 2017$. Barriers to sexual and reproductive healthcare services as experienced by female sex workers and service providers in Dhaka city, Bangladesh. PLoS One 12: e0182249.

6. Khanam R, Reza M, Ahmed D, Rahman M, Alam MS, Sultana S, Alam A, Khan SI, Mayer KH, Azim T, 2017. Sexually transmitted infections and associated risk factors among street-based and residence-based female sex workers in Dhaka, Bangladesh. Sex Transm Dis 44: 21-28.

7. Katz KR, McDowell M, Green M, Jahan S, Johnson L, Chen M, 2015. Understanding the broader sexual and reproductive health needs of female sex workers in Dhaka, Bangladesh. Int Perspect Sex Reprod Health 41: 182-190.

8. Rashid T, Auer S, 2015. "I am not like before": sex workers in Bangladesh's mega-brothel are stuck in a life of drugs and slavery. Vice News. Available at: https://news.vice.com/article/i-am-notlike-before-sex-workers-in-bangladeshs-mega-brothel-are-stuckin-a-life-of-drugs-and-slavery. Accessed March 5, 2020.

9. Clark J, 2015. Bangladesh's ignored female sex workers. BMJ 350: h3470. 
10. Wahed T, Alam A, Sultana S, Alam N, Somrongthong R, 2017. Sexual and reproductive health behaviors of female sex workers in Dhaka, Bangladesh. PLoS One 12: e0174540.

11. Alam N, Chowdhury ME, Mridha MK, Ahmed A, Reichenbach LJ, Streatfield PK, Azim T, 2013. Factors associated with condom use negotiation by female sex workers in Bangladesh. Int J STD AIDS 24: 813-821.

12. Bekker LG, Johnson L, Cowan F, Overs C, Besada D, Hillier S, Cates W, Jr, 2015. Combination HIV prevention for female sex workers: what is the evidence? Lancet 385: 72-87.

13. Mayaud P, Hawkes S, Mabey D, 1998. Advances in control of sexually transmitted diseases in developing countries. Lancet 351: S29-S32.

14. Patterson TL, Semple SJ, Chavarin CV, Mendoza DV, Santos LE, Chaffin M, Palinkas LA, Strathdee SA, Aarons GA, 2012. Implementation of an efficacious intervention for high risk women in Mexico: protocol for a multi-site randomized trial with a parallel study of organizational factors. Implement Sci 7: 105.

15. Feldblum PJ, Hatzell T, Van DammeK, Nasution M, Rasamindrakotroka A, Grey TW, 2005. Results of a randomised trial of male condom promotion among Madagascar sex workers. Sex Transm Infect 81: 166-172.

16. Basu I, Jana S, Rotheram-Borus MJ, Swendeman D, Lee SJ, Newman P, Weiss R, 2004. HIV prevention among sex workers in India. J Acquir Immune Defic Syndr 36: 845-852.

17. Rachakulla HK, Kodavalla V, Rajkumar H, Prasad SP, Kallam S, Goswami P, Dale J, Adhikary R, Paranjape R, Brahmam GN, 2011. Condom use and prevalence of syphilis and HIV among female sex workers in Andhra Pradesh, India - following a largescale HIV prevention intervention. BMC Public Health 11 (Suppl 6): $S 1$.

18. Wong ML, Chan R, Lee J, Koh D, Wong C, 1996. Controlled evaluation of a behavioural intervention programme on condom use and gonorrhoea incidence among sex workers in Singapore. Health Edu Res 11, 423-432.

19. Armstrong G, Medhi GK, Kermode M, Mahanta J, Goswami P, Paranjape R, 2013. Exposure to HIV prevention programmes associated with improved condom use and uptake of HIV testing by female sex workers in Nagaland, northeast India. BMC Public Health 13: 476.

20. Chow EP, Tung K, Tucker JD, Muessig KE, Su S, Zhang X, Jing J, Zhang L, 2015. Behavioral interventions improve condom use and HIV testing uptake among female sex workers in China: a systematic review and meta-analysis. AIDS Patient Care STDS 29: 454-460.

21. Morisky DE, Malow RM, Tiglao TV, Vissman AT, Rhodes SD, 2010. Reducing sexual risk among Filipina female bar workers: effects of a CBPR-developed structural and network intervention. AIDS Educ Prev 22: 371-385.

22. Wi T, Ramos ER, Steen R, Esguerra TA, Roces MC, Lim-Quizon MC, Neilsen G, Dallabetta G, 2006. STI declines among sex workers and clients following outreach, one time presumptive treatment, and regular screening of sex workers in the Philippines. Sex Transm Infect 82: 386-391.
23. de Walque D, Ed. 2013. Risking Your Health: Causes, Consequences, and Interventions to Prevent Risky Behaviors. Human Development Perspectives. Washington, DC: World Bank.

24. Packel L, Keller A, Dow WH, de Walque D, Nathan R, Mtenga S, 2012. Evolving strategies, opportunistic implementation: HIV risk reduction in Tanzania in the context of an incentive-based HIV prevention intervention. PLoS One 7: e44058.

25. de Walque $D$ et al., 2012. Incentivizing safe sex: a randomized trial of conditional cash transfers for HIV and sexually transmitted infection prevention in rural Tanzania. BMJ Open 2: e000747.

26. Rao V, Gupta I, Lokshin M, Jana SS, 2003. Sex workers and the cost of safe sex: the compensating differentia for condom use in Calcutta. J Dev Econ 71: 585-603.

27. Ramesh BM, Beattie TS, Shajy I, Washington R, Jagannathan L, Reza-Paul S, Blanchard JF, Moses S, 2010. Changes in risk behaviours and prevalence of sexually transmitted infections among HIV preventive interventions among female sex workers in five districts in Karnataka state, south India. Sex Transm Infect 86 (Suppl 1): i17-i24.

28. World Health Organization, 2002. Guidelines for the Management of Sexually Transmitted Infections in Female Sex Workers. Geneva, Switzerland: WHO. Available at: http://www.wpro. who.int/hiv/documents/docs/Guidelines_for_the_Mgt_of_STI_in_ female sex workers.pdf. Accessed September 28, 2017.

29. Salkovskis PM, Rimes KA, Warwick HMC, Clark DM, 2002. The health anxiety inventory: development and validation of scales for the measurement of health anxiety and hypochondriasis. Psychol Med 32: 843-853.

30. Satpathy GC, 2003. Encyclopaedia of AIDS. Delhi, India: Kalpaz Publications.

31. Family Health International, Bangladesh Country Office, 2007. The Effectiveness and Costs of Two Methods for the Systematic Prevention and Control of STIs, Among Female Sex Workers in Dhaka, Bangladesh. Available at: http://www.aidsdatahub.org/ sites/default/files/documents/The_Effectiveness_and_Costs_of Two_Methods_for_the_Systematic_Prevention_and_Control_of_

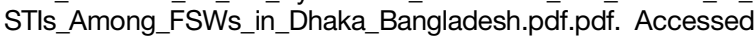
September 28, 2017.

32. Raudenbush SW et al., 2011. Optimal Design Software for Multilevel and Longitudinal Research (Version 3.01) [Software]. Available at: www.wtgrantfoundation.org.

33. Phrasisombath K, Thomsen S, Sychareun V, Faxelid E, 2012. Care seeking behaviour and barriers to accessing services for sexually transmitted infections among female sex workers in Laos: a cross-sectional study. BMC Health Serv Res 12: 37.

34. Bazzi AR, Rangel G, Martinez G, Ulibarri MD, Syvertsen JL, Bazzi SA, Roesch S, Pines HA, Strathdee SA, 2015. Incidence and predictors of HIV and sexually transmitted infections among female sex workers and their intimate male partners in northern Mexico: a longitudinal, multilevel study. Am J Epidemiol 181: 723-731.

35. Dupas P, Huillery E, Seban J, 2017. Risk information, risk salience, and adolescent sexual behavior: experimental evidence from Cameroon. J Econ Behav Organ 145: 151-175. 